\title{
DISCRIMINAÇÃO INSTITUCIONAL: UMA ANTIDISCRIMINAÇÃO DESCOLONIAL NA ANÁLISE DO RECORTE RACIAL EM ÉPOCA DE PANDEMIA
}

\author{
Rodrigo da Silva Vernes-Pinto ${ }^{1}$
}

\section{Resumo:}

O artigo problematiza sobre a possível configuração de Discriminação Institucional em casos de contaminação por Covid-19 em meio ao atual contexto de pandemia na sociedade brasileira. O trabalho objetiva aprofundar os estudos sobre o Direito da Antidiscriminação e suas categorias jurídicas, como os critérios proibidos de discriminação. Investiga-se sobre a hipótese se há Discriminação Institucional direcionada aos pretos, pardos e pobres e sobre a possível propositura de enfrentamento das situações discriminatórias com efeitos transformativos dessa realidade pela compreensão do Direito da Antidiscriminação em perspectiva descolonial. Foi utilizada metodologia jurídico-científica, uma abordagem dialética e a pesquisa do tipo qualitativa.

Palavras-chave: Direito da Antidiscriminação; Discriminação Institucional; Critérios Proibidos de Discriminação, Descolonialidade; Raça

\section{INSTITUTIONAL DISCRIMINATION: A DECOLONIAL ANTI-DISCRIMINATION IN THE ANALYSIS OF THE RACIAL PROFILE IN TIMES OF PANDEMIC}

\begin{abstract}
:
The paper discusses the possible configuration of Institutional Discrimination in cases of contamination by Covid-19 amid the current context of a pandemic in Brazilian society. The work aims to deepen the studies on Anti-Discrimination Law and its legal categories, such as the prohibited grounds of discrimination. It investigates the hypothesis of whether there is Institutional Discrimination directed at blacks, browns and the poor and on the possible proposition of facing discriminatory situations with transformative effects of this reality by understanding the Anti-discrimination Law in a decolonial perspective. Legal-scientific methodology, a dialectical approach and qualitative research were used.
\end{abstract}

Keywords: Anti-discrimination Law; Institutional Discrimination; Prohibited Grounds of Discrimination; Decoloniality; Race

\section{INTRODUÇÃO}

O surgimento da disciplina jurídica do Direito da Antidiscriminação representou avanço. O seu desenvolvimento e sistematização em categorias jurídicas próprias, representadas pelo seu dinamismo imanente, rompeu com uma realidade não-discriminatória

\footnotetext{
${ }^{1}$ Doutorando em Direito Público pela Unisinos - RS e Bolsista PROEX/CAPES. Mestre em Direitos Humanos pelo Centro Universitário Ritter dos Reis e Advogado. E-mail: rodrigodsilva@hotmail.com
} 
imbricada ao debate sobre o princípio jurídico da igualdade, sua promoção e distribuição de bens jurídicos. Assim, a compreensão sobre situações específicas de discriminação, nas quais há diferenciação injusta com o propósito ou efeito de impedir reconhecimento e/ou gozo de direitos em vários âmbitos da vida, conceito, inclusive, comtemplado em Convenções Internacional de Direitos Humanos, é proveniente do Direito da Antidiscriminação.

Em que pese isso, o estudo da igualdade e da não-discriminação mantém-se como terreno fértil de investigação, no qual a propositura de ferramentas antidiscriminatórias varia de acordo com a abordagem e a perspectiva adotada. Conforme isso se dá, há uma série de percepções, pois os conceitos, as categorias e institutos jurídicos da disciplina do Direito da Antidiscriminação estão insertos em espaços políticos e sociais refletidos no campo jurídico. Nessa toada, visões tradicionais e eurocentradas podem manter invisibilidades discriminatórias e ciclos de desigualdades experimentados por indivíduos e grupos subordinados, tanto na produção de conhecimento quanto na elaboração legislativa e na aplicação das leis. De outro modo, visões sob uma perspectiva descolonial se mostrariam atentas ao princípio da igualdade mais próximo às demandas históricas dos subalternizados, além de dinamizar ainda mais o Direito da Antidiscriminação, o que denotaria contributo para uma disciplina jurídica antidiscriminatória contemporânea.

Uma Antidiscriminação contemporânea permite um olhar alternativo às possíveis limitações constatadas na relação Estado Democrático de Direito, sujeito de direito, igualdade e não-discriminação. Ao passo que, em uma disciplina atrelada a preceitos modernos, há uma centralidade identitária dotada de universalidade na categoria de sujeito, em que a proteção jurídica direcionada pode não dar conta diante das complexidades de cenários discriminatórios a serem compreendidos e coibidos pelo Direito. Institutos, técnicas e conceitos jurídicos são elaborados ao longo do tempo dentro da Antidiscriminação. Um exemplo disso é a terminologia destacada nas categorias jurídicas traduzidas em critérios proibidos de discriminação, nas quais há a elaboração normativa atenta às identidades sociais subordinadas.

Mesmo assim, a resposta antidiscriminatória pode ser insuficiente ao considerar-se questões históricas e a localidade envolvida. Se a base investigativa e propositiva for alheia a realidade vivenciada, os resultados obtidos serão insatisfatórios.

Por conta disso, a experiência social na atualidade, na qual há uma pandemia sem precedentes, ao menos no que toca ao último século, é impactante nas demandas 
antidiscriminatórias. Isso assume contornos específicos no sul global, onde o Brasil está inserido. Enquanto a preocupação mundial acerca da pandemia por Covid-19 é a universalização dos infectados e a inviabilização dos sistemas de saúde, no Brasil, outros fatores são agregados. Por aqui, apesar de o vírus não escolher a quem infectar, os resultados morte, conforme dados oficiais, atingem uma camada social específica: pretos, pardos e pobres, o que escancara a desigualdade social no país. Este trabalho objetiva investigar a relação entre tais dados e a possibilidade de seu enfrentamento baseado em ferramentas para descortinar situações discriminatórias que invisibilizam tais situações.

Nessa esteira, a compreensão sobre uma perspectiva descolonial na proteção identitária antidiscriminatória aliada ao enfrentamento de estruturas de subordinação específicas e institucionalizadas no cenário brasileiro é um caminho para resultados igualitários, inclusivos e atento às diferenças. Para tanto, a busca de fontes de estudo e métodos interpretativos diversos da tradição moderna e atomizada mostra-se como um caminho potencial para essa investigação. Uma perspectiva sobre o tema a partir de estudos descoloniais, atento à produção de saberes insurgentes e contrahegemônicos, mostra-se fundamental. Como consequência, permite-se agregar novas bases doutrinárias para um Direito da Antidiscriminação de maior amplitude, com novas elaborações sobre categorias e institutos jurídicos.

Nessa investigação, utilizou-se como metodologia uma abordagem dialética com uma interpretação dinâmica e totalizante da realidade, isto no sentido de que os fatos não podem ser considerados fora de um contexto social, político, econômico, dentre outros, com a pesquisa qualitativa e de observação bibliográfica. Ao lado disso, outro vetor foi o da diferenciação entre uma posição metodológica jurídico-instrumental, centrada em dicotomias como legal e ilegal, isto é, na mera adequação da subsunção do caso à norma jurídica e uma posição metodológica jurídico-científico, a qual evita "perguntas binárias" e que não "ignora a pluralidade" (XIMENES, 2018, ps. 202-203). Com efeito, pautou-se em campo metodológico jurídico-científico, o qual permite-se a problematização das fontes do direito estudadas (XIMENES, 2018, p. 206), bem como a inquietação sobre a compreensão e aplicação de conceitos, categorias e institutos jurídicos, apontando para transformações de realidades discriminatórias. É o Direito conectado à realidade social (XIMENES, 2018, p. 207).

Dessa forma, o artigo é estruturado da seguinte forma: Na primeira parte, será abordada como as identidades traduzidas em critérios proibidos de discriminação se 
constituem e são fruto de narrativas próprias, dotadas de juridicidade. Em seguida, tratar-se-á da configuração jurídica das discriminações institucionais e socialmente estruturadas, bem como as suas dinâmicas, relacionando-as com o cenário de pandemia atual, principalmente tomando como vetor de análise o recorte racial. Ao final, abordar-se-ão as relações do problema da não discriminação relativa às identidades normatizadas e as discriminações estruturadas através de uma perspectiva descolonial.

\section{IDENTIDADES E CRITÉRIOS PROIBIDOS DE DISCRIMINAÇÃO}

Uma das contribuições do Direito da Antidiscriminação adveio da superação da discussão entre as faces formal e material da igualdade. Igualdade formal quando considerada de maneira genérica e universal, sem a atenção às diferentes características dos indivíduos e

grupos. É a igualdade dirigida ao legislador e com base na fórmula clássica o igual deve ser tratado igualmente, o que foi um avanço em termos de igualdade, mas nada acrescenta quanto às características dos indivíduos e grupos (ALEXY, 2011).

Ao difundir-se a Antidiscriminação, consolidou-se a compreensão dinâmica da isonomia, de forma capilar sobre todo ordenamento jurídico, com a oferta de categorias e instrumentos, assim como institutos e elementos sobre o conteúdo jurídico da igualdade (RIOS, 2008, p. 13). Se a igualdade e seus aspectos são vinculados a um caráter políticopreventivo, de promoção de isonomia e bem-estar social, o Direito da Antidiscriminação pelo princípio da não-discriminação é dotado de uma dimensão jurídico-repressiva (BORRILO, 2013, ps. 543-556).

Em sua dinamicidade, o Direito da Antidiscriminação condensou uma gama de conceitos, categorias jurídicas e institutos jurídicos. Dentre os quais, pode-se apontar o desenvolvimento e a elaboração de critérios proibidos de discriminação, nos quais há a previsão normativa de fatores protegidos pelos ordenamentos jurídicos em face de subordinações. O chamado Anti-discrimination Law ou Non-Discrimination Law proíbe determinadas situações discriminatórias através dos referidos critérios proibidos de discriminação, os quais são direcionados a quem deve ser protegido (FREDMAN, 2011, p. 109). Nessa linha, algumas características são listadas na lei, sendo consideradas como categorias proibidas de sofrerem algum tratamento discriminatório, tais como sexo, raça, cor, religião, etnia, dentre outras. Assim, para a existência de uma discriminação, tem que ocorrer 
alguma vinculação causal entre o tratamento desfavorável e o critério proibido ou não se estará frente a uma discriminação (BORRILLO, 2013).

Os elementos acima descritos são complementados pelo âmbito de proteção contra a não discriminação, onde os direitos fundamentais são protegidos, podendo se dar nas relações da vida privada, de propriedade, da família, até as relações laborais, previdência social e acesso a bens e serviços públicos (BORRILLO, 2013). Para a consideração de uma situação discriminatória, há a análise conjunta dos elementos do tratamento desfavorável e da violação de um critério proibido em um âmbito de proteção. Nesse caso, verifica-se o momento discriminatório e se há, por exemplo, a manutenção de privilégios, construção de hierarquias sociais e formação de estereótipos, no âmbito das dinâmicas discriminatórias onde se formam estruturas de subordinação.

O revelador disso tudo se dá através de um passo anterior e em perspectiva. A juridicidade pela eleição do critério proibido dá-se pelas próprias narrativas das identidades sociais envolvidas. A constatação disso possibilita um olhar apurado e perfunctório do problematizado, pois o influxo entre identidades e o meio social é contínuo. De forma jurídica, a relação é permanente entre critério proibido de discriminação e estruturas de subordinação. São justamente as narrativas interferentes nas identidades que são captadas pelo Direito e ganham status normativo. Se há um arranjo social capaz de atingir os projetos de vida e a autonomia dos indivíduos reconhecidos em um meio social (APPIAH, 2005) ou as suas classificações e estigmatizações sociais entre o que seria uma identidade social real e virtual (GOFFMAN, 2004), o jurídico segue as dinâmicas socialmente engendradas. Justamente no sentido de captar as interações de maneira a propor soluções antidiscriminatórias com o fim transformador de tais realidades.

Por isso, a análise de identidades traduzidas em critérios proibidos de discriminação requer conexões. Um possível entendimento ao trato das identidades raciais é pelo estabelecimento de ligações entre o racismo e as relações de poder (DELGADO, 2001, p. 2). Mais do que isso, a percepção de que o racismo é parte de uma série de atos discriminatórios que se renovam diariamente, de forma consciente ou não, naquilo que Richard Delgado (2001, p. 2) refere como "microagressões". Assim, essas relações se sedimentam em determinadas estruturas de poder e de discriminação, baseadas em padrões e estereótipos (DELGADO, 2001, ps. 26-28), cujas dinâmicas não visíveis devem ser descortinadas e combatidas. Como ferramenta analítica sobre o tema, parte-se de uma perspectiva crítica, em 
contraposição ao tradicional universalismo e abstração no que toca às identidades, sendo mister a constatação de contextos econômicos, sociais, políticos e históricos (DELGADO, 2001, p. 3). Assim, pensar sobre o racismo e sobre as identidades raciais não se restringe a um tipo de identidade, de forma universal e fixa, pois há diferenças em cenários sociais variados. Da mesma forma, isso reflete na interpretação das categorias jurídicas decorrentes das identidades.

Ao lado disso, merece atenção a ideia de que as identidades são construídas socialmente de acordo com contextos históricos (BEASLEY, 2006, p. 146). Nessa mirada, as identidades são parte de um processo em construção e de forma não acabada (BAUMAN, 1999, p. 50), de modo que sempre se constituem a partir de práticas discursivas e em uma multiplicidade de posições (HALL, 1996, p. 4). Aprofundando esse debate, também há a consideração de que as identidades são decorrência de atividades comportamentais e de convenções sociais que também advêm de relações definidas de poder (WEEKS, 2000, p. 28), a exemplo de poderes disciplinares (institucionalmente constituídos, como ensino, religião, medicina, direito) que impõem modelos dominantes, como ocorre em outras identidades como gênero e sexualidade (WEEKS, 2000, p. 41).

Nesse sentido, um Direito da Antidiscriminação eurocentrado e em uma perspectiva moderna pode ser limitado, como se verá mais adiante. Mesmo com a sistematização e aprofundamento pela experiência jurídica estadunidense no pós-guerra e na sua difusão pela Europa, o seu desenvolvimento partiu de uma restrita proteção identitária. Diante da consolidação de quem saiu vitorioso na Revolução Francesa, representada pela categoria fixa e universal do "homem branco, heterossexual, burguês, católico ou protestante", houve a sua contestação pelos estudos antidiscriminatórios, o que rendeu uma virada do ponto de vista da não-discriminação. Essa descentralização no sentido dado aos sujeitos de direito merecedores de proteção antidiscriminatória, entretanto, pode ser insuficiente para a captura de casos de subordinação não percebidos.

Ciclos discriminatórios não possuem a mesma característica em sociedades colonizadas, nas quais há uma marcante desumanização dos merecedores de proteção jurídica pelos direitos humanos. Exemplificativamente visível na discussão sobre questões raciais, de gênero ou em discriminações socialmente estruturadas e institucionalizadas. Com isso, é necessário um giro epistemológico capaz de atender às demandas antidiscriminatórias contemporâneas, o qual permita a adequação à realidade latino-americana, na teoria e na 
práxis, e que dê conta do atendimento de um fluxo de reconhecimento e proteção jurídica além de inspirações em sistemas jurídicos alienígenas.

Nesse jogo contínuo, em que se inclui ou se exclui no pertinente aos discriminados, o padrão interpretativo pode seguir uma Antidiscriminação de maior ou menor amplitude. Uma perspectiva eurocentrada em ambientes coloniais pode restringir o espectro de análise. A constatação de limites teóricos e práticos representa aspecto a ser enfrentado dentro de estudos relativos aos direitos humanos fundamentais e, em especial, ao Direito da Antidiscriminação. O não alcance efetivo, concreto e prático de sua disciplina jurídica, impossibilita o efeito transformativo de discriminações investigadas e constatadas. A análise dos impactos sofridos pela população vitimada pela pandemia por Covid-19 pode indicar para um menor ou maior grau de diferenciação injusta. Com isso, tanto nos planos individuais quanto nos planos coletivos relacionados a grupos discriminados, destaca-se a relevância em se aprofundar o estudo de alternativas antidiscriminatórias que preencham lacunas jurídicas. Um olhar atento a isso é campo seminal ao meio jurídico para avanços acadêmicos e sociais, os quais são potência para atingir uma maior gama de situações de vulnerabilidades e de subordinações fáticas e jurídicas.

\section{DISCRIMINAÇÃO INSTITUCIONAL/ESTRUTURAL - A PANDEMIA TERIA COR E CLASSE NO BRASIL?}

A assertiva de que as discriminações se dão além dos planos individuais ou coletivos (atingindo grupos minoritários) em contextos sociais é uma referência de que as subordinações podem também se dar institucionalmente (HENRY, 2010, p. 426). Por exemplo, é possível a constatação de racismo no conjunto de fatores e padrões que o mantém, como o encarceramento massivo de pretos e pobres (HENRY, 2010, p. 428). Tal situação é algo muitas vezes não perceptível e reproduzido pelas próprias instituições detentoras do poder e por aqueles determinadores das políticas públicas (HENRY, 2010, p. 429).

Diante disso, pode-se propor outro enfrentamento dos temas relativos às identidades, suas questões de pertencimento, hierarquização cultural, contraposição às relações de poder e a via e a desconstrução dos padrões emergentes de estruturas de subordinação. É a extensão do racismo cultural em um viés de racismo/discriminação institucional (HENRY, 2010 p. 431), em que atos institucionalizados fomentam círculos e padrões de discriminação 
perpetuadores de desigualdades a grupos identitários (como os pretos) e com base em protocolos institucionais (HENRY, 2010, p. 435). Nesse sentido, as hierarquizações, estereótipos e construção de privilégios de uma branquitude em diversas instituições e em detrimento da negritude são caracterizadores da discriminação institucional.

A atualidade social experimentada pela pandemia por Covid-19 esgrime uma série de fatores que levam justamente ao enfrentamento do mencionado. A "democracia" da contaminação pelo vírus que não escolhe o seu receptor, quando se trata do efetivo tratamento dos acometidos pela doença, traz à baila uma realidade diferente. A realidade dos excluídos, dos esquecidos, dos necessitados, dos colocados à margem do sistema político-social-jurídico. Mesmo que haja uma universalização dos acessos individualizados em tal sistema, na prática, verifica-se dificuldades da garantia e respeito aos direitos normatizados. Os dados oficiais e institucionalizados no combate à Covid-19 (BRASIL, 2020) são esclarecedores sobre o assunto:

Figura1

TABELA 9 Óbitos por Sindrome Respiratória Aguda Grave (SRAG), segundo classificação final e raça, 2020 até SE 31

\begin{tabular}{|c|c|c|c|c|c|c|c|}
\hline \multirow[b]{2}{*}{ Raça } & \multicolumn{7}{|c|}{ Óbitos por Sindrome Respiratória Aguda Grave (SRAG) } \\
\hline & COVID-19 & Influenza & $\begin{array}{l}\text { Outros virus } \\
\text { respiratórios }\end{array}$ & $\begin{array}{c}\text { Outros agentes } \\
\text { etiológicos }\end{array}$ & $\begin{array}{c}\text { Não } \\
\text { especificado }\end{array}$ & $\begin{array}{c}\text { Em } \\
\text { Investigação }\end{array}$ & Total \\
\hline Branca & 25.249 & 111 & 60 & 145 & 14.286 & 1.298 & 41.149 \\
\hline Preta & 4.621 & 12 & 9 & 18 & 2.089 & 237 & 6.986 \\
\hline Amarela & 1.018 & 6 & 3 & 6 & 433 & 37 & 1.503 \\
\hline Parda & 32.185 & 119 & 56 & 140 & 12.997 & 1.030 & 46.527 \\
\hline Indigena & 350 & 1 & 1 & 1 & 80 & 10 & 443 \\
\hline Ignorado & 13.115 & 31 & 33 & 25 & 4.736 & 468 & 18.408 \\
\hline Sem informação & 14.435 & 27 & 32 & 33 & 5.382 & 498 & 20.407 \\
\hline Total & 90.973 & 307 & 194 & 368 & 40.003 & 3.578 & 135.423 \\
\hline
\end{tabular}

Fonte: SIstema de Informação da Viglâncla Epldemılológlca da Grlpe. Dados atualizados em 03 de agosto de 2020 às $12 \mathrm{~h}$, sujeltos a revisōes.

Com base no relatório indicado, ficou evidenciado que o recorte de raça/cor parda e preta é o mais frequente no tangente ao número de óbitos por Covid-19 no Brasil. A variação de dados é grande desde o início da pandemia e a utilização do quadro estatístico não é definitivo. Assim como no que se refere a esta investigação jurídico-científica. A relação empírica com as perspectivas antidiscriminatórias aqui discutidas serve mais como uma inquietação acadêmica momentânea, a qual pode se confirmar na prática e no desenvolvimento de outros trabalhos além deste artigo. De qualquer forma, o que é sintomático até o presente momento é o conjunto de dados estatísticos indicando para um 
padrão de cor naqueles que mais morrem no Brasil por Covid-19. Considerando o histórico social de desigualdades brasileiro, no qual há uma constante exclusão social e econômica de pobres, pretos e pardos, há indícios de uma configuração discriminatória. O percentual maior de óbitos sobre essa camada da população, decorrente da pandemia, pode ser lido como um tipo de discriminação estruturada e de forma institucionalizada, mesmo que sem o propósito direto de discriminar.

Vale ressaltar que muitas vezes a discriminação institucional se dará de forma não aparente e não intencional (HENRY, 2010, p. 437), o que demonstra a necessidade de se questionar essas situações e atingir resultados antidiscriminatórios concretos e transformadores da realidade injustamente posta. Diante de padrões de exclusão e desigualdades persistentes aos grupos identificados com minorias políticas, como os pretos e pardos, as soluções passam pelo exame das dinâmicas discriminatórias, pela resistência nos cenários institucionalizados e em enfrentamento às hegemonias (SHEPPARD, 1998, p. 146).

Da mesma forma, a análise não pode se dar alheia aos efeitos da tradição moderna, devendo ser atenta à verificação contemporânea de cada caso discriminatório e de maneira descolonizadora. Isso pode se dar dentro das instituições e revelar as práticas reforçadoras das desigualdades, cujos efeitos podem ser definidos como discriminação sistêmica, em que as práticas institucionais interagem e produzem a exclusão de membros de grupos minoritários (SHEPPARD, 1998, p. 157). Nesse sentido, a análise contextualizada não só no âmbito social em que as identidades se relacionam, mas no interior das instituições e suas estruturas e sistemas reforçadores de discriminação merecem uma atenta análise.

\section{ANTIDISCRIMINAÇÃO E UMA PERSPECTIVA DESCOLONIAL}

A perspectiva descolonial eleita é parte de uma visão crítica, em contraposição à tradição moderna no que toca aos conceitos, categorias e institutos jurídicos, pois atenta aos contextos econômicos, sociais, políticos e históricos (DELGADO, 2001, p. 3).

Essa atenção crítica e democrática é alinhada à insurgência dos saberes subalternizados e contrahegemônicos. Como reflexo, permite-se a produção de conhecimentos descoloniais (MISKOLCI, 2014, ps. 1-3) através do perscrutar sobre as limitações vivenciadas pelas vozes subalternizadas (SPIVAK, 2020), para uma fundamentação teórica e 
prática da Antidiscriminação. Uma via a ser pavimentada ao lado de um constitucionalismo transformativo no que se refere à efetividade de direitos humanos fundamentais, com ideias descoloniais do sul global, oportunizando mudanças sociais e jurídicas significativas. O caminho a trilhar é emancipatório em comparação ao tradicional constitucionalismo liberal (BAXI, 2013), ou seja, interpretar normas jurídicas de direitos humanos fundamentais de acordo com cada realidade discriminatória e sua localidade.

A função de bases descoloniais é de rompimento de tradições limitantes. E isso está contido na análise discursiva sobre as identidades traduzidas em critérios proibidos de discriminação. Assim como, no que toca às estruturas de poder e de subordinação constantes em discriminações institucionais. A exemplo do investigado por Edward Said em sua obra "Orientalismo" (SAID, 1990), é discutir academicamente os discursos utilizados na compreensão de tais identidades e estruturas de maneira não vinculada a uma adstrita epistemologia moderna e centrada em padrões eurocentrados. É verificar a colonialidade do poder (QUIJANO, 2005), traço constituinte da América Latina, cujo padrão ocasionou hegemonia no modo relacionado aos saberes, à epistemologia e ao poder-jurídico estabelecido. Como na chamada "lógica da colonialidade", na qual se atinge a própria noção desumanizadora dos detentores de direitos (BRAGATO, 2016), pode-se compor uma lógica de colonialidade dos saberes e da configuração de conceitos, categorias e institutos jurídicos, o que deve ser repensada e debatida pelo Direito da Antidiscriminação.

Abordar o humano e o desumano, sob a ótica descolonial, insere-se no debate sobre o alcance das políticas públicas institucionalizadas, as quais podem agir em detrimento de um recorte racial e de classe quanto ao tratamento de saúde e mortes decorrentes da pandemia por coronavírus. É justamente na visão de quem é mais ou menos humano no merecimento de atenção quanto aos protocolos institucionais de acesso ao direito à saúde que o problema se desenvolve. A exclusão reiterada dos mais necessitados, pretos e pardos, em um padrão institucional impacta diferenciadamente de maneira injusta na atenção Estatal a tais indivíduos e grupos. Isso seria indicativo de um padrão discriminatório, o que deve ser captado e coibido pelo Direito. Logo, a categorização jurídica de tais identidades em critérios proibidos de discriminação em institutos jurídicos próprios como o da discriminação institucional é representativa, mas pode necessitar de complementação.

Nessa proposta de quebra paradigmática, insere-se a ideia de um chamado giro descolonial (SARTORI JÚNIOR, 2017) em contestação de saberes e suas ampliações em suas 
abordagens e perspectivas, para além de uma dinâmica moderna das relações científicas e jurídicas, naquilo que Boaventura de Souza Santos chamou de uma "cartografia moderna dual nos âmbitos epistemológicos e jurídicos" (SANTOS, 2009, p. 76). Em uma lógica chamada de "pensamento moderno abissal" com bases de reconhecimento e de não reconhecimento, isto é, legitimador daquilo que é humano e subumano através de linhas abissais (SANTOS, 2009, p. 76). Como o autor refere, para além dessas linhas, há a propositura de novos caminhos epistêmicos, a partir de uma "epistemologia do sul" em um confronto entre a "monocultura da ciência moderna com uma ecologia de saberes" (SANTOS, 2009, p. 85).

Essa renovação epistemológica e acadêmica, na qual se revela a heterogeneidade e a pluralidade dos saberes e da produção científica, proporciona novos objetivos na elaboração de concepções e institutos jurídicos transformadores de realidades. Em diálogo com Mignolo, o desafio é "producir conocimiento con perspectiva de futuro a partir de categorías de pensamiento que fueron subalternizados y categorizados como racionales o no racionales a lo largo de la construcción y expansión del mundo moderno/colonial” (MIGNOLO, 2000, p. 22).

A adoção dessa perspectiva descolonial também se relaciona, exemplificativamente, com as questões de mestiçagem e contempla os excluídos pela lógica colonial de saberes e poderes jurídicos instituídos por uma tradição restrita. Sob essa visão, é atender à mujer mestiza referida por Glória Anzaldúa, considerada alienada na cultura dominante e insegura dentro de sua própria cultura, fluindo entres os espaços e interstícios de poder de dois mundos (ANZALDÚA, 1999, p. 42). Como decorrência, propõe-se um Direito da Antidiscriminação aberto às realidades daqueles que percorrem uma cartografia social por vezes não abordada e que impõe subordinação. Nisso tudo, objetiva-se novos significados ao criar-se pontes ao reconhecimento de diversas demandas, sejam políticas, sociais, raciais, de gênero, enfim, em atenção ao conjunto de identidades. Mara Viveros ensina:

\footnotetext{
busca uma reapropriação e um deslocamento do significado do caráter mestiço de nossa história, ....um projeto inacabado de luta para criar um espaço ('a ponte') onde seria possível reunir e desconstruir simultaneamente as diferentes experiências íntimas e reivindicações políticas, raciais, sexuais e de gênero que conformam essa identidade. Nossa América é o projeto da Nova Mestiça e uma crítica à ideia de que existe um 'mestiço universal'. É também a afirmação da capacidade de ressonância que produz habilidade para viver nos limites, na fronteira, nesse espaço Che'je onde coexistem, em tensão e em conversação, o colonial e o colonizado. Falar de Nossa América em vez de América Latina é, finalmente, escolher uma denominação que não foi criada nos contextos acadêmicos hegemônicos metropolitanos para dar conta de experiências sociais particulares (VIVERO VIGOYA, 2018, ps. 29-30).
} 
A par as questões terminológicas e o neologismo proposto pela autora, isso serve de diretriz a esta investigação. A mestiçagem como elemento necessário a uma Antidiscriminação contemporânea é característica das identidades nacionais latinoamericanas, sempre lembrando que não se desconecta da questão racial como marcador social de hierarquização e não se traduz em universalidade (VIVEROS VIGOYA, 2012, p. 283). Com efeito, indica-se para o necessário aprofundamento dos estudos antidiscriminatórios modernos para uma perspectiva descolonial e contemporânea, cujas bases ampliem o espectro de análise identitária-critérios proibidos de discriminação e das estruturas de subordinação vivenciadas nas sociedades da Latino América. Uma contemporaneidade não sintetizada em uma definição, mas parte de um conjunto de elementos que compõem processos culturais, políticos, econômicos e sociais (HENNIGEN, 2007, p. 192). Justamente que possibilite o contemplar do plural e das diferenças da experiência (HENNIGEN, 2007, p. 206) de indivíduos e grupos, de forma aberta à produção do conhecimento.

Esses referenciais possibilitam ferramentas interpretativas do problema investigado com uma profundidade capaz de revelar ciclos discriminatórios invisíveis. Ao lado, permite assumir bases propositivas para, 1) o enfrentamento antidiscriminatório na seara jurídica, dentro da chamada dimensão jurídico-repressiva de desigualdades e subordinações; e, 2) até mesmo servindo de vetor político-preventivo, de cunho promocional quanto à igualdade e em casos de políticas públicas. Assim sendo, se há um influxo contínuo de identidades, seus reconhecimentos pelas narrativas desaguam na normatização de critérios proibidos de discriminação. Nessa linha, as suas inserções em estruturas de subordinação com apurada compreensão da realidade vivenciada, permitirá enfrentamentos transformativos. Exemplo disso é a dinâmica social e, porventura discriminatória, no tratamento dos infectados na pandemia por Covid-19, a qual denuncia um atendimento deficitário da população parda e preta no que tange ao direito à saúde, redundando em impactante número de mortes acima da média relativa à população branca no Brasil.

Isso também revela o quanto a abordagem de categorias jurídicas e institutos jurídicos, como os critérios proibidos de discriminação, atrelada à tradição e a uma agenda moderna e atomizada no indivíduo é limitadora à disciplina da Antidiscriminação. Ver as identidades não isoladas e com uma perspectiva desestabilizadora de padrões impostos por discurso vindos de relações de poder e de desconstrução de estruturas de subordinação auxilia no efetivo combate de contextos discriminatórios. Seguindo o fio proposto nesta investigação, a proibição de 
discriminação em estruturas de subordinação institucionalizadas a partir de uma contextualização abstrata não permitiria a captura do fenômeno jurídico-social do não atendimento da camada social atingida em sua maior parte pelos óbitos nos casos de Covid-19 no Brasil. Em contrapartida, a análise dessa realidade e seus dados a partir do prisma descolonial, com base no binômio humano-desumano, permite captar as sutilezas do fenômeno desigual e de diferenciação injusta.

O proposto é um avançar nas linhas de perspectivas, em que se vislumbra a complexa análise de contextos de injustiça e discriminação, nos quais, não só o discurso de não neutralidade e de atenção à vulnerabilidade de indivíduos e grupos deve ser a tônica. Também é parte disso o exame sobre a efetiva adoção de soluções transformativas de desigualdades e subordinações. Em um caminho, no qual a perspectiva eleita estabeleça um método interpretativo e de compreensão conectado com o constante questionar sobre os modelos e estruturas que dão sustentabilidade para a construção de conceitos, categorias e institutos jurídicos. A pergunta deve girar em torno, no caso da pandemia por Covid-19 e as possíveis exclusões pelo recorte racial, de que raça e de qual discriminação estruturada se está lidando em conjunto com a localidade e como o contexto social se constituiu no tempo. Para tanto, uma perspectiva descolonial mostra-se viável ao atendimento das hipóteses descortinadas, o que pode ser explorado através da pesquisa aqui elaborada.

É justamente o apropriar-se de uma epistemologia além da tradição moderna, a qual se fornece um instrumental interpretativo com potencial para incluir os que estão às margens de um sistema padronizado de exclusões. A busca incessante por igualdade e não discriminação é contemplada pela coibição de negação de direitos não só dentro de um binômio igualdade e desigualdade ou discriminar e não-discriminar entre indivíduos identificados em paradigmas comportamentais e culturais. Além disso, o fim é o de humanizar os que são desumanizados pela lógica colonial que reflete, na contemporaneidade, um cotidiano social excludente dos marginalizados, os esquecidos em sua cor não integrada no ideal de branquitude ou em sua classe hierarquizada no acesso a bens e serviços ou gentrificada por uma geografia de afastamento dos grandes centros urbanos.

Uma pandemia na qual há indícios de que o tratamento dado pelo Poder Público aos atingidos assume menor rigor em defesa de indivíduos e grupos identificados com as minorias políticas já expostas, assume contornos de maior gravidade no que toca às demandas antidiscriminatórias. Por isso, a contribuição de uma visão descolonial ao Direito da 
Antidiscriminação em face às estruturas de subordinação e relações de poder existentes, pode contribuir para o aprofundamento de uma disciplina antidiscriminatória realmente transformadora dos subalternizados em cada contexto social discriminatório a ser enfrentado na contemporaneidade. Exatamente como na situação examinada neste trabalho.

\section{CONSIDERAÇÕES FINAIS}

Esta investigação teve como origem uma inquietação sobre os reflexos da pandemia por Covid-19 no Brasil, mormente com relação aos seus impactos em um recorte específico da população: os pretos e pardos. A partir de dados oficiais, constatou-se no mês de agosto de 2020, uma diferença no percentual óbitos pela pandemia atingindo tal camada populacional. Relacionando o recorte racial com o histórico de desigualdade social experimentando neste país, é possível que haja o componente agregado da pobreza, de forma interseccional, na constatação do maior atingimento de pretos, pardos e pobres pelos óbitos por Covid-19 na sociedade brasileira.

Como ressaltado, a presente pesquisa é fruto de uma suspeita, a qual, diante da variação contínua dos dados na pandemia, pode se confirmar na prática ou não. Mesmo assim, é possível relacionar os dados empíricos referidos com as dinâmicas sociais e discriminatórias constatadas diariamente. Em decorrência disso, há indicativos de discriminação institucional a atingir do específico grupo subordinado, o qual tem sido tema de estudos e propostas antidiscriminatórias.

Aliado a isso, propôs-se o aprofundamento do tema através de uma Antidiscriminação sob uma perspectiva descolonial. Uma disciplina jurídica além de uma visão moderna e eurocentrada, cujos critérios proibidos de discriminação precisam ser atentos às identidades não fixas herdadas de uma tradição atomizada e não relacional dentro de ambientes sociais. Com efeito, o prisma descolonial propicia o questionamento sobre o desumanizar contido em sociedades cuja herança é a lógica da colonialidade. Logo, um olhar atento a essa realidade viabiliza uma rede de questionamentos acerca das subordinações ocasionadas a indivíduos e grupos, aqui, os pretos, pardos e pobres. Nesse caminho, buscouse perscrutar o tema e problema através de método jurídico-científico, no qual se evitou restringir-se às perguntas sobre legalidade e ilegalidade. Buscou-se a compreensão do 
problematizado pela pluralidade, com a problematização das categorias jurídicas estudadas, como os critérios proibidos de discriminação e discriminação institucional.

O proposto foi o de um giro epistemológico descolonial, em que às bases científicas são agregadas outras visões, cujo espectro de análise é dotado de maior amplitude para a transformações efetivas de realidades discriminatórias. Mesmo que, o aprofundamento dos dados sobre o problema aqui levantado ainda seja necessário, os indícios, como já dito, são uma chamada à reflexão acadêmica. Isso, por si só, representa uma caminhada inicial para o desenvolvimento científico de uma Antidiscriminação descolonial como ferramenta de análise e para uma maior inclusão no debate jurídico, atendendo as mais diversas e diferentes identidades protegidas de discriminações.

\section{REFERÊNCIAS}

ALEXY, Robert. Teoria dos direitos fundamentais. 2. ed. São Paulo: Malheiros, 2011.

ANZALDÚA, Glória. Borderlands. La frontera. 2. ed. São Francisco: Aunt Lute Books, 1999.

APPIAH, Anthony. The Ethics of Identity. Princeton: Princeton University Press, 2005

BAUMAN, Zygmunt. Ensaios sobre o conceito de cultura. Rio de Janeiro: Zahar, 1999.

BAXI, Upendra. Preliminary Notes on transformative constituionalism. Transformative constitutionalism: Comparing the apex courts of Brazil, India and South Africa. South Africa: Pulp, 2013.

BEASLEY, Chris. Gender \& Sexuality. Critical Theories, Critical Thinkers. London: Sage Publications, 2006.

BORRILO, Daniel. Elementos para una teoría general de la igualdad y la no-discriminación a partir de la experiencia del derecho europeo. In Revista de la Faculdad de Derecho PUCP, n. 71, 2013. 
BRASIL. MINISTÉRIO DA SAÚDE. Boletim epidemiológico especial. Secretaria da Vigilância do Ministério da Saúde. Disponível em: < https://coronavirus.saude.gov.br/boletins-epidemiologicos> Acesso em: 27 set 2020.

BRAGATO, Fernanda Frizzo. Discursos desumanizantes e violação seletiva de direitos humanos sob a lógica da colonialidade. In Quaestio Iuris, vol. 09, nº. 04, Rio de Janeiro.

DELGADO, Richard. Critical Race Theory An Introduction. New York and London: New York University Press, 2001.

FREDMAN, Sandra. Discrimination law. 2. ed. New York: Oxford University Press, 2011.

GOFFMAN, Erving. Estigma: notas sobre a manipulação da identidade deteriorada. Márcia Bandeira de Mello Leite Nunes (trad.). Rio de Janeiro: LTC, 1975.

HALL, Stuart. Who Needs 'Identity'?. Questions of Cultural Identity. London: Sage Publications, 1996.

HENNIGEN, Inês. A contemporaneidade e as novas perspectivas para a produção de conhecimentos. Cadernos de Educação, vol. 29, julho-dezembro, 2007.

HENRY, P.J. Institutional Bias. The Sage Handbook of prejudice, stereotyping, and discrimination. Califórnia: Sage Newburg Park, ps. 426-440.

MIGNOLO, Walter D. Diferencia colonial y razón postoccidental. La reestruturación de las ciencias sociales em América Latina. Bogotá: Santiago Castro-Gomez, 2000.

MISKOLCI, Richard. "Um saber insurgente ao sul do Equador". Periodicus, Salvador, v. 1, n. 1, p. 1-25, maio/out. 2014.

QUIJANO, Anibal. Colonialidade do poder, Eurocentrismo e América Latina. A colonialidade do saber: eurocentrismo e ciências sociais. Perspectivas latino-americanas, 2005. Disponível em: <http://bibliotecavirtual.clacso.org.ar/clacso/sursur/20100624103322/12_Quijano.pdf>Acesso em: 15 mai. 2020.

RIOS, Roger Raupp. Direito da antidiscriminação: discriminação direta, indireta e ações afirmativas. Porto Alegre: Liv. do Advogado, 2008. 
SAID, Edward W. Orientalismo. São Paulo: Companhia das Letras, 1990.

SANTOS, Boaventura de Souza. Para além do pensamento abissal: das linhas globais a uma ecologia dos saberes. In: SANTOS, Boaventura de Souza; MENESES, Maria Paula (Orgs.). Epistemologias do sul. Coimbra: CES, 2009,

SARTORI JUNIOR, Dailor. Pensamento descolonial e direitos indígenas: uma crítica à tese do "Marco temporal da ocupação". Rio de Janeiro: Lumen Juris, 2017.

SHEPPARD, Collen. Equality Rights and Institutional Change: Insights from Canada and the United States. In: Heinonline 15 Ariz. J. Int'l \& Comp. L. 143 1998, content downloaded/printed from HeinOnline (http://heinonline.org) Sat Aug 8 16:09:26 2015.

SPIVAK, Gayatri Chakravorty. Pode o subalterno falar? Belo Horizonte: Editora UFMG, 2020 .

VIVEROS VIGOYA, Mara. Race and Sex in Latin America. Peter Wade. Revista Colombiana de Antropología, vol. 48, núm. 1, enero-junio, 2012.

As cores da masculinidade: experiências interseccionais e práticas de poder na Nossa América. Rio de Janeiro: Papéis Selvagens, 2018, p. 29-30.

WEEKS, Jeffrey. O corpo e a sexualidade. O corpo educado. $2^{\text {a }}$ edição. Belo Horizonte: Autêntica, 2000.

XIMENES, Julia Marmann. Por que o problema continua sendo problema? Diferenciando Pesquisa Jurídico-Instrumental e Pesquisa Jurídico-Científica e o Papel das Fontes do Direito. Revista Direito Público, Porto Alegre, Vol. 15, n. 82, 2018. 